\title{
Agreement between self-reported and measured weight and height collected in general practice patients: a prospective study
}

Sze Lin Yoong ${ }^{1 *}$, Mariko Leanne Carey ${ }^{1}$, Catherine D'Este ${ }^{1,2}$ and Robert William Sanson-Fisher ${ }^{1}$

\begin{abstract}
Background: Self-reported weight and height is frequently used to quantify overweight and obesity. It is however, associated with limitations such as bias and poor agreement, which may be a result of social desirability or difficulties with recall. Methods to reduce these biases would improve the accuracy of assessment of overweight and obesity using patient self-report. The level of agreement between self-reported and measured weight and height has not been widely examined in general practice patients.

Methods: Consenting patients, presenting for care within four hour sessions, were randomly allocated to the informed or uninformed group. Participants were notified either a) prior to (informed group), or b) after (uninformed group) reporting their weight and height using a touchscreen computer questionnaire, that they would be measured. The differences in accuracy of self-report between the groups were examined by comparing mean differences, intraclass correlations (ICCS), Bland Altman plot with limits of agreement (LOAs) and Cohen's kappa. Overall agreement was assessed using similar statistical methods.

Results: Of consenting participants, 32\% were aged between 18-39 years, 42\% between 40-64 years and 25\% were 65 years and above. The informed group $(n=172)$ did not report their weight and height more accurately than the uninformed group $(n=160)$. Mean differences between self-reported and measured weight $(p=0.4004)$, height $(p=0.5342)$ and body mass index (BMI) $(p=0.4409)$ were not statistically different between the informed and uninformed group. Overall, there were small mean differences $\left(-1.2 \mathrm{~kg}\right.$ for weight, 0.8 for height and $-0.6 \mathrm{~kg} / \mathrm{m}^{2}$ for BMI) and high ICCS (>0.9) between self-reported and measured values. A substantially high kappa (0.70) was obtained when using self-reported weight and height relative to measured values to quantify the proportion underweight, normal weight, overweight or obese. While the average bias of self-reported weight and height as estimates of the measured quantities is small, the LOAs indicate that substantial discrepancies occur at the individual level.
\end{abstract}

Conclusions: Informing patients that their weight and height would be measured did not improve accuracy of reporting. The use of self-reported weight and height for surveillance studies in this setting appears acceptable; however this measure needs to be interpreted with care when used for individual patients.

Keywords: Obesity, Family practice, Weight

\footnotetext{
*Correspondence: Sze.Yoong@newcastle.edu.au

${ }^{1}$ Priority Research Center for Health Behavior \& Hunter Medical Research Institute, Newcastle Australia, University of Newcastle, Callaghan 2308,

Australia

Full list of author information is available at the end of the article
}

\section{() Biomed Central}

(c) 2013 Yoong et al.; licensee BioMed Central Ltd. This is an Open Access article distributed under the terms of the Creative Commons Attribution License (http://creativecommons.org/licenses/by/2.0), which permits unrestricted use, distribution, and reproduction in any medium, provided the original work is properly cited. 


\section{Background}

Overweight and obesity affects a large proportion of the population in the developed world [1]. As the access point for health care systems in countries including Australia, Canada and United Kingdom, general practice is a valuable setting to target the reduction of overweight or obesity. GPs have access to a large proportion of the population, with $81 \%$ of Australians aged 15 years and above reporting having consulted their GP at least once a year [2]. Both GPs [3] and patients [4,5] perceive weight management to be part of a physicians' role and those who are advised to lose weight by a health care provider are more likely to attempt to lose weight [6].

Self-reported weight and height is commonly used to assess overweight and obesity as it enables the body mass index (BMI) to be calculated. In the general practice setting, self-reported weight and height is often utilised in large-scale monitoring studies, where it may not be feasible to carry out weight and height measurements. For example, the largest ongoing study with general practice patients in Australia (the Bettering the Evaluation and Care of Health (BEACH)) uses selfreported weight and height to provide surveillance data on prevalence of overweight or obesity [7]. While selfreport is a relatively cost-effective, practical and less invasive way of obtaining weight and height, this method of assessment is subject to a number of limitations such as bias or poor agreement, which may be a result of social desirability or difficulties with recall [8]. Previous population studies have reported that using self-reported weight and height frequently leads to an underestimation of overweight and obesity when compared to measured values $[9,10]$. Most studies examining the accuracy of self-report have however been conducted in the general population [9,11-13]. In order to utilise self-report for monitoring of overweight or obesity in this setting, the accuracy of self-reported weight and height in general practice patients' needs to be evaluated.

Simple strategies to improve self-reported weight and height could potentially be useful in helping improve surveillance of excess weight in general practice. One strategy that has been used to improve the reporting of socially undesirable behaviours is the bogus pipeline method [14]. Using this method, respondents are given the impression that the accuracy of their responses will be independently checked. It is underpinned by the assumption that people are more likely to tell the truth when they think that their responses will be verified [15]. Black et al. tested the effectiveness of a variation of this method in improving accuracy of self-reported weight and height in volunteers in a shopping mall [16]. Participants in the intervention group were informed that their weight and height would be measured and then asked to report their weight and height; whilst those in the control group reported their weight and height before being told that they would be measured [16]. Participant in the intervention group reported their weight and height significantly more accurately than those in the control group. Despite its' potential to improve accuracy of self-reported weight and height, no other study examining this intervention exists, to our knowledge.

This study therefore aimed to test whether advising general practice patients that their height and weight would be measured was effective in improving accuracy of self-report. It also aims to provide an index of reliability and agreement for self-reported weight and height in general practice patients, collected using a touchscreen computer, using mean differences, intraclass correlations (ICC) and Bland Altman plots with 95\% limit of agreements (LOAs). The impact of self-report on categorization of underweight, normal weight, overweight and obesity was also assessed using Cohen's kappa. An additional aim was to determine whether mean difference in reporting of self-reported and measured weight, height and BMI varied by age category.

\section{Methods}

This study was conducted as part of a larger study testing the acceptability of using a touchscreen computer questionnaire in twelve general practices in Australia [2]. A subsample of patients from three practices was invited to participate in the current study. Consecutive patients aged 18 years and above, presenting for an appointment to their GP and able to provide informed consent were eligible to participate. Patients were not excluded based on the presence of other health conditions. Research staff recorded the sex of all invited patients in order to assess for consent bias. Participants were randomised to the informed or uninformed group and completed a touchscreen computer questionnaire. Participants' weight and height measurements were obtained after completion of the questionnaire.

\section{Experimental groups}

General practice sessions (4 hours) were centrally randomised by the researcher to the informed or uninformed group using a random number table. Participants recruited within the one session were all allocated to the same group. Neither practice staff nor patients were aware of group allocation.

\section{Informed group}

Participants' consent to have their weight and height measured was sought prior to commencement of the questionnaire. After consenting to have their measurements taken, participants provided their self-reported weight and height using the touchscreen questionnaire. 


\section{Uninformed group}

Participants provided their self-reported height and weight as part of completion of the questionnaire. The research assistant asked for consent to obtain weight and height measurements after participants provided their self-reported weight and height.

\section{Variables}

\section{Self-report}

Participants were asked to provide demographic information including gender and whether they had a government concession health card. Patients were asked to select their age from the following categories: $1=18-24$; $2=25-29 ; 3=30-34 ; 4=35-39 ; 5=40-44 ; 6=45-49 ; 7=$ $50-54 ; \quad 8=55-59 ; \quad 9=60-64 ; \quad 10=65-69 ; \quad 11=70$ and above. Participants also reported weight in either kilograms $(\mathrm{kg})$ or stones/pounds and height in centimetres $(\mathrm{cm})$ or feet/inches. All weight responses were converted to $\mathrm{kg}$ and height response converted to $\mathrm{cm}$.

\section{Measured}

Participants' weight was obtained using a digital body fat and muscle weighing scale and height measured with participants head in the Frankfort plane using a mounted stadiometer. Participants were asked to remove their shoes, any heavy outer garments and personal belongings prior to measurement. Weight was measured to the nearest $0.1 \mathrm{~kg}$ and height to the nearest $0.1 \mathrm{~cm}$. A trained anthropometrist took patients' weight and height measurements twice. A third measurement was taken if there was more than a $10 \%$ variation between the first and second measurement.

\section{Ethical approval}

Ethical approval was provided by the University of Newcastle Human Research Ethics Committee (H20090341) and ratified by the University of New South Wales HREC (HREC 09393/ UN H-2009-0341) and Monash University HREC (2009001860).

\section{Data analysis}

STATA SE version 11.0 (StataCorp, College Station, Tex, USA) was used to perform all statistical analyses. Selfreported values of height larger than $240 \mathrm{~cm}$ and smaller than $120 \mathrm{~cm}$ and values of weight larger than $250 \mathrm{~kg}$ and less than $30 \mathrm{~kg}$ were coded as missing as these values were perceived to be errors in self-report. BMI was calculated from both self-reported and measured data using weight in $\mathrm{kg}$ divided by metres squared. Consent rates for physical measures were compared between the informed and uninformed groups. Differences between self-reported and measured values were obtained for weight, height and BMI. Mean differences, ICCs and corresponding 95\% CIs for height, weight and BMI were tabulated separately for the informed and uninformed groups and compared between groups using student's t-test for mean differences and by comparing 95\% CIs for ICCs $[17,18]$. Bland Altman plots with 95\% LOA for height, weight and BMI were generated for both groups. The Bland Altman test is a statistically robust method of assessing reliability and agreement [19]. Additionally, Cohen's kappa statistic and 95\% CI for classification of underweight (BMI $<18.5 \mathrm{~kg} / \mathrm{m}^{2}$ ), normal weight (BMI $\geq$ $18.5 \mathrm{~kg} / \mathrm{m}^{2}$ and $<25 \mathrm{~kg} / \mathrm{m}^{2}$ ), overweight (BMI $\geq 25 \mathrm{~kg} /$ $\mathrm{m}^{2}$ and $<30 \mathrm{~kg} / \mathrm{m}^{2}$ ) or obesity (BMI $\left.\geq 30 \mathrm{~kg} / \mathrm{m}^{2}\right)$ was generated and compared between groups using 95\% CIs. The overall level of agreement between self-reported and measured weight, height and BMI was also assessed. Mean differences between self-reported and measured values and corresponding standard deviations for males and females were reported. An ICC for the overall sample was calculated to provide an estimate of reliability. Cohen's kappa was calculated to provide the level of agreement between self-reported and measured classification of BMI categories. The degree of agreement between patient measured and self-reported overweight and obesity was assessed as follows: $\kappa<0$ is none/poor; $0 \leq \kappa \leq 0.20$ is slight; $0.21 \leq \kappa \leq 0.40$ is fair; $0.41 \leq \kappa \leq 0.60$ is moderate; $0.61 \leq \kappa \leq 0.80$ is substantial; and $0.81 \leq \kappa \leq$ 1.0 is almost perfect [20]. Mean differences in selfreported weight and height were reported by age group. An ANOVA test was carried out to compare the mean difference in reporting by age (collapsed as 18-24, 25$44,45-64$ and $\geq 65$ years).

\section{Sample size calculation}

An initial sample size calculation was calculated to detect a difference of $0.5 \mathrm{~kg} / \mathrm{m}^{2}$ in mean BMI between the two groups, with $80 \%$ power and $95 \%$ significance level, assuming a standard deviation of 1.5. To achieve this, a minimum of 142 participants needed to be recruited into each group (284 patients overall). A sample of this size would allow detection of a difference $+/-0.02$ in mean ICCs between groups with $80 \%$ power, at $5 \%$ significance, assuming a standard deviation of 0.5 . For overall agreement, this number of patients would allow estimation of kappa with $95 \%$ confidence within $+/-0.1$, for a kappa of 0.4 or higher [21]. This sample size would also allow us to detect an ICC of 0.7 or more as being significantly greater than 0.6 [22]. A sample size of approximately 300 (75 per age group) would have at least $80 \%$ power, with $5 \%$ significance, to detect a difference in the variation between self-reported and measured weight, height and BMI of 0.6 standard deviations.

\section{Results}

Overall, $86 \%$ of patients consented to completing the questionnaire for the larger study. 355 patients were 
asked if they were willing to have their weight and height measured and 93\% $(n=332)$ consented. No significant differences in proportion of males and females who consented to and did not consent to being measured were identified $\left(x^{2}: 1.1304, d f=1 ; p=0.288\right)$. There was no significant difference in the proportion who consented to being measured between the informed (93\%) and uninformed (92\%) group $\left(\chi^{2}: 0.9213, \mathrm{df}=1\right.$; $\mathrm{p}=0.337)$.

Eleven participants reported having a height of more than $240 \mathrm{~cm}$ or less than $120 \mathrm{~cm}$ and/or having a weight of more than $250 \mathrm{~kg}$ or less than $30 \mathrm{~kg}$. One participant in the uninformed group was excluded as the height difference tabulated was beyond reasonable error rate. More than half (56\%) of consenting participants were female, $25 \%$ were aged 65 years and above and $42 \%$ had a government subsidised health care card. $14.2 \%$ of the Australian population are aged 65 years above [23]. While not directly comparable due to the inclusion of those aged below 18 in the latter population statistics, the current sample had a larger proportion of older people ( $\geq 65$ years) than would be expected in the general population. This larger proportion of older participants is consistent with that identified in other general practice datasets [7]. Demographic characteristics are presented for the informed $(n=172)$ and uninformed $(n=160)$ groups (see Table 1$)$.

There were no significant differences in mean difference of self-reported and measured weight $(p=0.4004)$, height $(\mathrm{p}=0.5342)$ and BMI $(\mathrm{p}=0.4409)$ and ICCs between the informed and uninformed group (see Table 1).

When measured and self-reported BMI categories were examined the percentage agreement was $78 \%$ for the informed group and $81 \%$ for the uninformed group. The kappa values were 0.68 [95\% CI 0.58, 0.78] for the informed and 0.72 [95\% CI 0.61, 0.83] for the uninformed group and overlap between 95\% CIs indicated no significant differences.

The Bland-Altman plots for weight, height and BMI for the informed and uninformed groups are shown in Figures 1, 2 and 3.

As there were no significant differences in accuracy of self-reported weight and height between the groups, the sample was pooled to assess overall agreement and reliability. Overall mean differences between self-reported and measured values were $-1.2 \mathrm{~kg}$ (4.0) for weight [males $-1.2 \mathrm{~kg}$ (3.6), females $-1.2 \mathrm{~kg}(4.4)], 0.8 \mathrm{~cm}$ (4.4) for height [males $1.5 \mathrm{~cm}$ (3.5); females $0.3 \mathrm{~cm}$ (4.9)] and $-0.6 \mathrm{~kg} / \mathrm{m}^{2}$ (2.0) for BMI [males $-0.9 \mathrm{~kg} / \mathrm{m}^{2}$ (1.7); females $\left.-0.4 \mathrm{~kg} / \mathrm{m}^{2}(2.3)\right]$. The overall ICCs for selfreported and measured values and their corresponding 95\% CIs were $0.97[0.97,0.98]$ for weight, 0.91 [0.89, 0.93] for height and 0.94 [0.91, 0.95] for BMI. The Bland Altman plots and LOA provide an indication of the
Table 1 Mean difference and intraclass correlation for weight, height and BMI for informed and uninformed group

\begin{tabular}{lcc}
\hline Group & $\begin{array}{c}\text { Informed } \\
(\mathbf{n}=\mathbf{1 7 2})^{*}\end{array}$ & $\begin{array}{c}\text { Uninformed } \\
(\boldsymbol{n}=160)^{* *}\end{array}$ \\
\hline Sexn (\%) & $78(45)$ & $69(43)$ \\
Male & $94(55)$ & $91(57)$ \\
Female & & \\
Age n (\%) & $60(35)$ & $48(30)$ \\
18-39 & $67(39)$ & $74(46)$ \\
$40-64$ & $45(26)$ & $38(24)$ \\
$65+$ & $71(42)$ & $66(42)$ \\
Number with concession health care & & \\
(\%) & & \\
Mean difference ${ }^{\text {a }}$ (sd) $[95 \%$ Cl] & & \\
Weight & $-1.0(4.5)$ & $-1.4(3.5)$ \\
& {$[-9.8,7.8]$} & {$[-8.1,5.4]$} \\
Height & $0.7(3.9)[-6.9$, & $1.0(5.0)$ \\
& $8.2]$ & {$[-8.7,10]$} \\
BMl & $-0.6(2.2)$ & $-0.7(1.9)$ \\
& {$[-4.8,3.7]$} & {$[-4.4,3.0]$}
\end{tabular}

ICC $[95 \%$ Cl]

Weight $\quad 0.97[0.96,0.98] \quad 0.98[0.97,0.99]$

Height $\quad 0.92[0.90,0.94] \quad 0.90[0.87,0.93]$

BMI $\quad 0.93[0.91,0.95] \quad 0.94[0.93,0.96]$

ICC: Intraclass correlation; Cl: confidence interval; BMI: Body Mass Index; sd: standard deviation.

${ }^{a}$ mean difference calculated using self-reported weight minus measured weight.

*Missing data for informed group: 3 missing for weight, 3 missing for height; subsequently 6 missing for BMI.

**Missing data for uninformed group: 2 missing for weight, 6 missing for height; subsequently 6 missing for BMI.

extent of underreporting and overreporting of weight, height and BMI when compared to measured values (see Figures 1, 2, 3).

The overall percentage agreement between selfreported and measured classification of BMI categories was $80 \%$ [ $95 \%$ CI 75, 84]. Twenty percent of those who were overweight were categorised as normal weight using self-reported weight and height (see Table 2). Of those who were obese, $22 \%$ were classified as overweight using self-reported weight and height. The prevalence of obesity was underestimated by $5 \%$ (35\% using measured and $30 \%$ using self-report) and prevalence of normal weight was overestimated by $5 \%$ ( $27 \%$ using measured and $32 \%$ using self-report). The kappa for categorisation of BMI was 0.70 [95\% CI 0.63, 0.77]; representing substantial agreement [20] and that level of agreement was greater than expected by chance alone $(\mathrm{p}<0.001)$.

There were no significant differences by age, when mean differences in measured and self-reported weight, height and BMI were compared (see Table 3). 


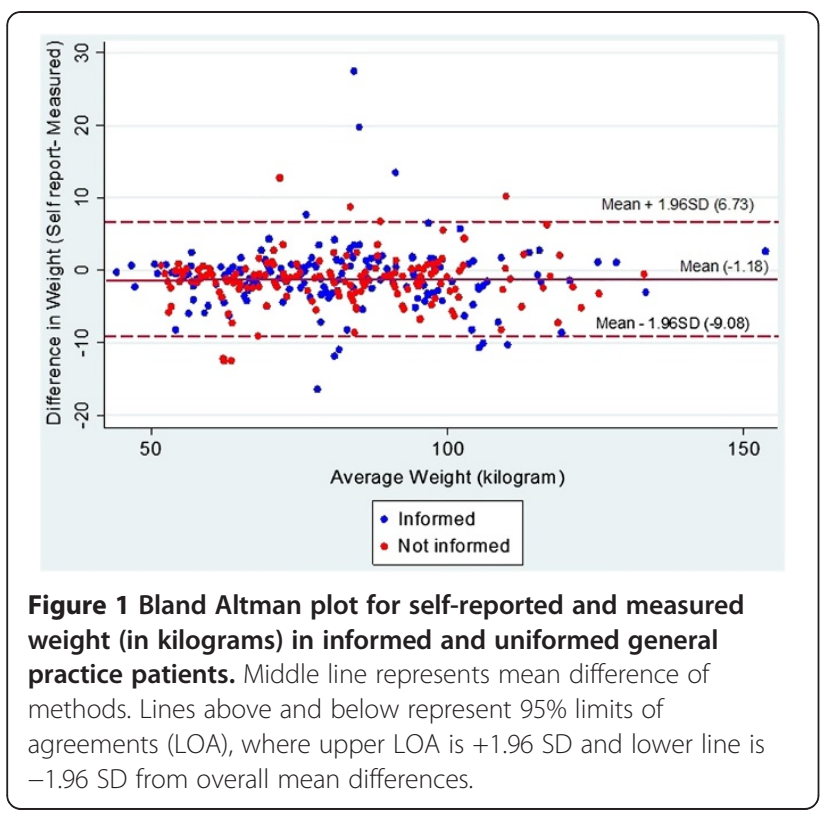

\section{Discussion}

This study demonstrated that informing general practice patients that their height and weight would be measured did not improve accuracy of self-report. This contrasts with Black and colleagues' findings, where those who were informed that they would be measured reported their weight and height significantly more accurate than those who were not informed [16]. This difference in findings could have occurred due to several differences in study methodology, setting, participants and statistical analyses conducted. Black and colleagues recruited their sample for a health screen in a shopping mall whereas

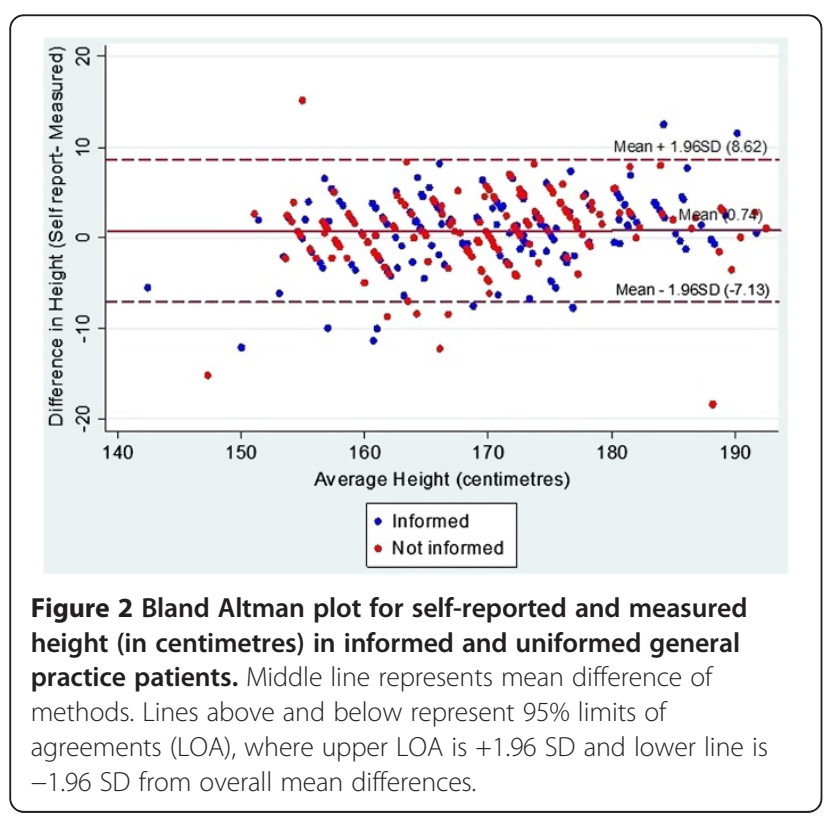

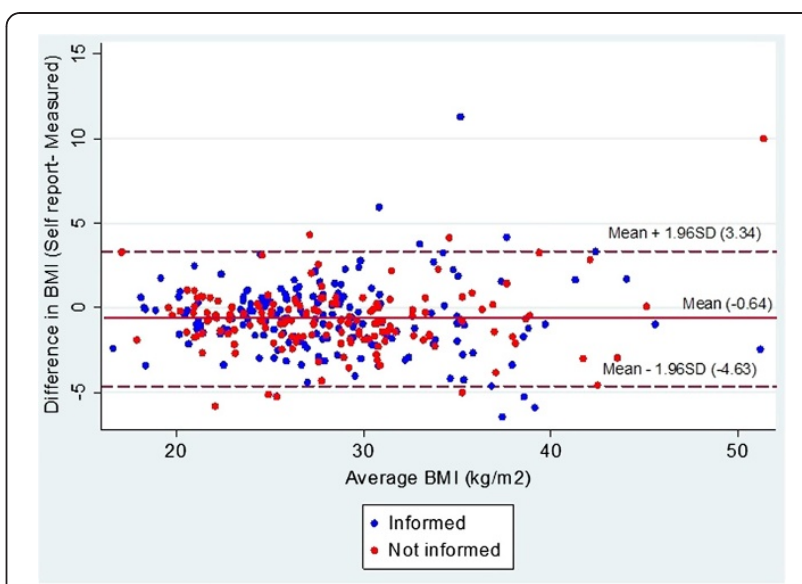

BMI: Body Mass index

Figure 3 Bland Altman plot for self-reported and measured body mass index (in $\mathrm{kg} / \mathrm{m}^{2}$ ) in informed and uniformed general practice patients. Middle line represents mean difference of methods. Lines above and below represent 95\% limits of agreements (LOA), where upper LOA is +1.96 SD and lower line is $-1.96 \mathrm{SD}$ from overall mean differences.

the current study recruited participants presenting for general practice care. General practice patients may be more willing to disclose their weight and height compared to volunteers in a shopping mall. Further, Black's study included only participants aged between 18 to 28 years whereas only a small proportion (18\%) of our sample was aged between 18 and 29 years [16]. Those in the younger age bracket may be more likely to be affected by cultural ideals regarding weight and height [24], which might have led to attempts to misreport these measures. Inconsistent findings regarding the accuracy of self-reported weight and height in older patients have been identified, with one longitudinal study reporting that only small changes in reporting of weight and height occurred with increasing age [25] and others identifying substantial differences between measured and self-reported weight and height in those older [26,27]. Our study did not find any significant differences in mean reporting of self-reported and measured values with age category; and no pattern of increasing or decreasing difference with age was observed. Black and colleagues also asked participants in the informed group six additional 'body weighing questions' which may have helped with recall of weight [16]. The current study aimed to test solely if informing patients that their weight and height would be measured would improve accuracy of self-report and thus did not include these questions. Given that GPs see a larger proportion of older patients, reporting of weight and height in this group may be less affected by social desirability bias and suggests that misreporting may be attributed largely to recall bias or not having an accurate knowledge of one's 
Table 2 Categorisation of body mass index (BMI) category based on self-reported and measured weight and height

\begin{tabular}{|c|c|c|c|c|c|}
\hline \multirow[b]{2}{*}{ Self-report } & \multicolumn{4}{|c|}{ Measured $\mathrm{n}(\%)^{\mathrm{b}}$} & \multirow[t]{2}{*}{ Total $^{a}$} \\
\hline & Underweight & Normal weight & Overweight & Obese & \\
\hline Underweight & $4(67)$ & $2(2.3)$ & $0(0)$ & $0(0)$ & $6(1.9)$ \\
\hline Normal weight & $2(33)$ & $78(91)$ & $23(20)$ & $0(0)$ & $103(32)$ \\
\hline Overweight & $0(0)$ & $6(7.0)$ & $85(74)$ & $25(22)$ & $116(36)$ \\
\hline Obese & $0(0)$ & $0(0)$ & $7(6.1)$ & $88(78)$ & $95(30)$ \\
\hline Total & $6(1.9)$ & $86(27)$ & $115(36)$ & $113(35)$ & 320 \\
\hline
\end{tabular}

${ }^{a}$ Total less than overall included due to invalid values in self-reported weight and height.

${ }^{b}$ Percentage reported is proportion of measured for each BMI category.

Underweight defined as BMI $<18.5 \mathrm{~kg} / \mathrm{m}^{2}$; Normal weight defined as $\mathrm{BMI} \geq 18.5 \mathrm{~kg} / \mathrm{m}^{2}$ and $<25 \mathrm{~kg} / \mathrm{m}^{2}$; Overweight defined as BMI $\geq 25 \mathrm{~kg} / \mathrm{m}^{2}$ and $<30 \mathrm{~kg} / \mathrm{m}^{2}$; Obese defined as BMI $\geq 30 \mathrm{~kg} / \mathrm{m}^{2}$.

current weight and height. Future studies testing this intervention in younger patients may produce different findings.

Consistent with findings in other populations [8], participants in the present study tended to underreport their weight and overreport their height. Mean differences between self-reported and measured weight $(-1.2 \mathrm{~kg}$ in males; $-1.2 \mathrm{~kg}$ in females $)$ and height $(1.5 \mathrm{~cm}$ in males; $0.3 \mathrm{~cm}$ in females) are within the range of that identified in a review examining accuracy of selfreported weight $(-1.9 \mathrm{~kg}$ to $0.4 \mathrm{~kg}$ in males; $-1.6 \mathrm{~kg}$ to $0.7 \mathrm{~kg}$ in females) and height $(-1.3 \mathrm{~cm}$ to $2.3 \mathrm{~cm}$ in males; $-1.7 \mathrm{~cm}$ to $2.2 \mathrm{~cm}$ in females) in the general population [8]. Only one Australian study was included in the review, however this study did not report mean differences. When compared to other Australian studies, our study had lower mean differences in self-reported and measured values for reporting of height and weight, particularly for females. Taylor et al. identified mean differences of $-1.5 \mathrm{~kg}$ in males; $-1.8 \mathrm{~kg}$ in females for weight and $1.4 \mathrm{~cm}$ in males; $1.3 \mathrm{~cm}$ in females for height [12]. Another study identified mean differences of $2.0 \mathrm{~cm}$ in males; $0.8 \mathrm{~cm}$ in females for height and $-1.4 \mathrm{~kg}$ for males and $-3.0 \mathrm{~kg}$ for females [13]. There is some evidence to suggest that females who had recently consulted a doctor may be able to more accurately recall their weight and height [28]. Additionally, patients presenting for care to their GP may represent a more 'health conscious' sample and thus, may be more aware

Table 3 Mean difference between measured and selfreported weight, height and BMI by age categories in Australian general practice patients

\begin{tabular}{|c|c|c|c|c|c|c|c|}
\hline & \multicolumn{4}{|c|}{ Mean difference* (standard deviation) } & \multicolumn{3}{|c|}{ ANOVA test } \\
\hline & $\begin{array}{l}18-24 \\
(n=33)\end{array}$ & $\begin{array}{l}25-44 \\
(n=95)\end{array}$ & $\begin{array}{c}45-64 \\
(n=121)\end{array}$ & $\begin{array}{c}\geq 65 \\
(n=83)\end{array}$ & $\mathbf{F}$ & df & $\begin{array}{c}\mathrm{p}- \\
\text { value }\end{array}$ \\
\hline Weight & $-1.6(0.6)$ & $-0.8(0.4)$ & $-1.1(0.4)$ & $-1.6(0.4)$ & 0.73 & 3 & 0.5344 \\
\hline Height & $-0.004(1.0)$ & $1.2(0.6)$ & $0.7(0.3)$ & $0.9(0.4)$ & 0.67 & 3 & 0.5695 \\
\hline $\mathrm{BMI}$ & $-0.6(0.3)$ & $-0.5(2.0)$ & $-0.6(0.2)$ & $-0.9(0.2)$ & 0.63 & 3 & 0.5950 \\
\hline
\end{tabular}

*Mean calculated using measured self-reported minus measured values. of their weight and height measurements. Differences could also be attributed to the fact there was no time lag between self-report and measured assessments in our study, whereas an average of 23.5 days between selfreported and measured data was reported in the study conducted by Taylor [12].

Overall, $80 \%$ of participants were accurately classified as underweight, normal weight, overweight or obese using self-reported weight and height. The use of selfreported BMI resulted in no difference in prevalence of overweight and only a 5\% lower prevalence of obesity when compared to estimates obtained using measured data. These findings are favourable when compared to other studies which indicate that self-reported data underestimated the proportion of participants classified as overweight by $2 \%$ to $12 \%$ and obese by approximately $7 \%[12,13]$. The present findings however, are comparable to the 2008 Australian National Health Survey, which identified a $6 \%$ rate of underestimation of prevalence of overweight or obese when self-reported data was compared to measured data [10].

While the current study identified high reliability between self-reported and measured weight and height, represented by high ICCs $(>0.9)$ for weight, height and BMI, the estimated Bland Altman LOAs suggests that accuracy of individuals' self-report may vary. When compared to measured weight, inaccuracies in self-reported weight ranged from overestimation of $6.7 \mathrm{~kg}$ to underestimation of $9.1 \mathrm{~kg}$. Similarly, inaccuracies in self-reported height ranged from an overestimation of $8.6 \mathrm{~cm}$ to underestimation of $7.1 \mathrm{~cm}$. This subsequently led to overreporting of BMI by $3.3 \mathrm{~kg} / \mathrm{m}^{2}$ and underreporting of up to $4.6 \mathrm{~kg} / \mathrm{m}^{2}$.

\section{Strengths and limitations}

A high consent rate was achieved, with 93\% agreeing to have their weight and height measured. This high consent rate may be due to the use of the touchscreen computer which could have provided participants with a more private way of reporting weight and height. There was no time lapse between provision of self-report and actual 
measurement of weight and height, thus reducing potential error attributed to weight change during the time lapse. The use of ICCs and Bland Altman plots with LOAs provide a more robust examination of agreement compared to the more traditionally used Pearson's correlation coefficients as it provides an indication of variability and agreement rather than association. The ICC however treats self-reported and measured values as exchangeable (i.e. method of measurement is assumed to be a random effect). When systematic differences between methods of measurement occur, high ICCs may not necessarily imply high agreement.

Some of the variation between self-reported values and measured values may be accounted for by the way in which participants report their weight and height (e.g. end-digit preferences [12] and reporting in imperial units rather than metric). A large proportion of participants included in this study were aged 65 years and above. However, when mean differences in self-reported and measured values were compared, no differences were identified between older and younger participants. This study was conducted in only three practices, potentially limiting the generalizability of findings. No significant differences in participant's sex was observed when compared to a larger Australian general practice dataset (BEACH), which included 95,839 patient encounters recruited by 958 GPs [7]. However, a difference in distribution of age was observed between our sample and the $\mathrm{BEACH}$ dataset [7].

\section{Conclusion}

Informing general practice patients that their weight and height would be measured did not significantly improve accuracy of self-report. Testing this strategy in subgroups likely to be affected by cultural ideals regarding weight (i.e. younger, female) may be beneficial in helping identify ways to improve accuracy of self-report for these groups. Selfreported weight and height provides relatively accurate estimates of BMI in Australian general practice patients. Thus, in circumstances where population trends are of interest such as in large surveillance studies, self-report is likely to be an accurate alternative. While the average bias of selfreported weight and height as estimates of the measured quantities is small, the LOAs indicate that there is a need for these values to be interpreted with caution in individuals.

\section{Competing interest}

The authors declare no competing interest.

\section{Authors' contributions}

SY, MC, CD and RSF all participated in conception of the study and survey design. SY conducted all data collection and initial data analysis. SY, MC and CD had input into the statistical analysis. All authors offered critical comments on the draft of the manuscript and approved the final submitted version.

\section{Acknowledgements}

The authors would like to thank all participating practices and patients. This work was supported by a grant from beyondblue and National Heart Foundation of Australia Strategic Research Partnership [G 08S 4042]; and the Cancer Institute of New South Wales (08/RFG/1-20). Data analyses were supported by the University of Newcastle Priority Research Centre for Health Behaviour Statistical Funding grant. The authors would like to thank Daniel Barker for his assistance with statistical analyses.

\section{Author details}

'Priority Research Center for Health Behavior \& Hunter Medical Research Institute, Newcastle Australia, University of Newcastle, Callaghan 2308, Australia. ${ }^{2}$ Center for Clinical Epidemiology and Biostatistics, University of Newcastle, Callaghan 2308, Australia.

Received: 25 August 2012 Accepted: 5 March 2013

Published: 13 March 2013

\section{References}

1. World Health Organization (WHO): Obesity and overweight. Available from: http://www.who.int/mediacentre/factsheets/fs311/en/.

2. Australian Bureau of Statistics: Health Service: Use and patient experience. Available from: http://www.abs.gov.au/ausstats/abs@.nsf/Lookup/ BF1313C0400DA15BCA25792E000D5B86?opendocument 2011.

3. Campbell K, Engel H, Timperio A, Cooper C, Crawford D: Obesity management: Australian General Practitioners' Attitudes and Practices. Obes Res 2000, 8(6):459-466.

4. Tham M, Young D: The role of the General Practitioner in weight management in primary care-a cross sectional study in General Practice. BMC Fam Pract 2008, 9:66.

5. Tan D, Zwar NA, Dennis SM, Vagholkar S: Weight management in general practice: what to patients want? Med J Aust 2006, 185(2):73-75.

6. Galuska DA, Will JC, Serdula MK, Ford ES: Are health care professionals advising obese patients to lose weight? JAMA 1999, 282(16):1576-1578.

7. Britt H, Miller GC, Charles J, Henderson J, Bayram C, Valenti L, Harrison C, Pan Y, O'Halloran J, Zhang C, et al: General practice activity in Australia 201011. General practice series no. 29. Sydney: Sydney University Press; 2011.

8. Gorber SC, Tremblay M, Moher D, Gorber B: A comparison of direct vs. self-report measures for assessing height, weight and body mass index: a systematic review. Obes Rev 2007, 8(4):307-326.

9. Elgar FJ, Stewart JM: Validity of self-report screening for overweight and obesity. Evidence from the Canadian Community Health Survey. Can J Public Health 2008, 99(5):423-427.

10. Australian Bureau of Statistics: 4364.0- National Health Survey: Summary of Results, 2007-2008 (Reissue). Available online from: http://www.abs.gov.au/ AUSSTATS/abs@.nsf/Lookup/4364.0Main+Features12007-2008\%20\% 28Reissue\%29?OpenDocument.

11. Burton NW, Brown W, Dobson A: Accuracy of body mass index estimated from self-reported height and weight in mid-aged Australian women. Aust NZ J Publ Heal 2010, 34(6):620-623.

12. Taylor AW, Grande ED, Gill TK, Chittleborough CR, Wilson DH, Adams RJ, Grant JF, Phillips P, Appleton S, Ruffin RE: How valid are self-reported height and weight? A comparison between CATI self-report and clinic measurements using a large cohort study. Aust N Z J Public Health 2006, 30(3):238-246

13. Flood V, Webb K, Lazarus R, Pang G: Use of self-report to monitor overweight and obesity in populations: some issues for consideration. Aust N Z J Public Health 2000, 24(1):96-99.

14. Roese NJ, Jamieson DW: Twenty years of bogus pipeline research: a critical review and meta-analysis. Psychol Bull 1993, 114(2):363-375.

15. Jones $E E$, Sigall $H$ : The bogus pipeline: a new paradigm for measuring affect and attitude. Psychol Bull 1971, 76(5):349-364

16. Black DR, Taylor AM, Coster DC: Accuracy of self-reported body weight: Stepped Approach Model component assessment. Health Educ Res 1998 13(2):301-307.

17. Shrout P, Fleiss J: Intraclass correlations: uses in assessing rater reliability. Psychol Bull 1979, 86(2):420-428.

18. Morton AP, Dobson AJ: Assessing agreement. Med J Australia 1989, 150(7):384-387.

19. Bland JM, Altman DG: Statistical methods for assessing agreement between two methods of clinical measurement. Lancet 1986, 1(8476):307-310. 
20. Landis JR, Koch GG: The measurement of observer agreement for categorical data. Biometrics 1977, 33(1):159-174.

21. Flack VF, Afifi AA, Lachenbruch PA, Schouten HJA: Sample size determinations for the two rater kappa statistic. Psychometrika 1988 53(3):321-325

22. Shoukri MM, Asyali MH, Donner A: Sample size requirements for the design of reliability study: review and new results. Stat Methods Med Res 2004, 13(4):251-271.

23. Australian Bureau of Statistics: Australian Demographic Statistics. Available from: http://www.abs.gov.au/ausstats/abs@.nsf/mf/3101.0 2012.

24. Ziebland S, Thorogood M, Fuller A, Muir J: Desire for the body normal: body image and discrepancies between self reported and measured height and weight in a British population. J Epidemiol Community Health 1996, 50(1):105-106

25. Dahl AK, Hassing LB, Fransson El, Pedersen NL: Agreement between selfreported and measured height, weight and body mass index in old age-a longitudinal study with 20 years of follow-up. Age Ageing 2010, 39(4):445-451

26. Lawlor DA, Bedford C, Taylor M, Ebrahim S: Agreement between measured and self--reported weight in older women. Results from the British Women's Heart and Health Study. Age Ageing 2002, 31(3):169-174.

27. Kuczmarski MF, Kuczmarski RJ, Najjar M: Effects of age on validity of selfreported height, weight, and body mass index: findings from the Third National Health and Nutrition Examination Survey, 1988-1994. J Am Diet Assoc 2001, 101(1):28-34. quiz 35-26.

28. Villanueva E: The validity of self-reported weight in US adults: a population based cross-sectional study. BMC Public Health 2001, 1(1):11.

doi:10.1186/1471-2288-13-38

Cite this article as: Yoong et al: Agreement between self-reported and measured weight and height collected in general practice patients: a prospective study. BMC Medical Research Methodology 2013 13:38.

\section{Submit your next manuscript to BioMed Central and take full advantage of:}

- Convenient online submission

- Thorough peer review

- No space constraints or color figure charges

- Immediate publication on acceptance

- Inclusion in PubMed, CAS, Scopus and Google Scholar

- Research which is freely available for redistribution 